\title{
Electrochemical Co-deposition of Nickel Oxide and Polyaniline
}

\author{
Xu-Yuan Peng ${ }^{\mathrm{a}}$, Xiao-Xia Liu ${ }^{\mathrm{a}, *}$, Pei-Jie Hua ${ }^{\mathrm{a}}$, Dermot Diamond ${ }^{\mathrm{b}}$, King-Tong Lau ${ }^{\mathrm{b}, \#}$ \\ ${ }^{a}$ China-Ireland Center for Advanced Materials and Sensor Development, Department \\ of Chemistry, Northeastern University, Shenyang, 110004, China \\ ${ }^{\mathrm{b}}$ China-Ireland Center for Advanced Materials and Sensor Development, National \\ Centre for Sensor Research, Dublin City University, Glasnevin, Dublin 9, Ireland \\ Correspondence: *xxliu@mail.neu.edu.cn, Tel: +862483683642, fax: 862423600159 \\ "Kim.lau@dcu.ie, Tel: +35317006008, Fax: +35317007995
}

\begin{abstract}
Nickel oxide $\left(\mathrm{NiO}_{\mathrm{x}}\right)$ and polyaniline (PAni) were electro-co-deposited from $\mathrm{NiSO}_{4}$ and aniline through cyclic voltammetric scans to afford PAni-NiOx composite film at controlled $\mathrm{pH}$ environment. The electrochemical activities of the film were investigated by cyclic voltammetry in $0.1 \mathrm{M} \mathrm{NaOH}$ and $0.1 \mathrm{M} \mathrm{H}_{2} \mathrm{SO}_{4}$, respectively. Typical redox couples of PAni in $0.1 \mathrm{M} \mathrm{H}_{2} \mathrm{SO}_{4}$ appeared at $c a .0 .2 \mathrm{~V}$ and $0.4 \mathrm{~V} v s$. SCE; $\mathrm{Ni}(\mathrm{II}) / \mathrm{Ni}$ (III) redox couple was observed at ca. $0.4 \mathrm{~V} v$ s. SCE in $0.1 \mathrm{M} \mathrm{NaOH}$. The morphologies and elemental components of the films were inspected by Scanning Electron Microscopy (SEM) and Energy Dispersive X-ray Diffraction (EDX). The stability of nickel oxide in the films was found to be enhanced against acidic environments. Electrochemical catalytic behavior of $\mathrm{NiO}_{\mathrm{x}}$ within the composite film was conserved and demonstrated by catalytic oxidation of methanol and ethanol.
\end{abstract}

Keywords: Nickel oxide $\cdot$ Polyaniline $\cdot$ Composite film $\cdot$ Electrocatalysis 


\section{INTRODUCTION}

Organic-inorganic composites have attracted considerable attention as they can combine the advantages of both components and may offer special properties through reinforcing or modifying each other [1]. Polyaniline (PAni) has been the subject of many studies due to its oxygen and moisture-stability and potential applications in many fields [2]. PAni can also provide good network for inorganic components and modify properties and stability of the latter [3]. Nickel oxide has received considerable attention due to potential applications in many fields such as electrochromics, electrocatalysis, supercapacitor etc [4-7]. Chemically synthesised PAni and NiO composite by Song and coworkers produced PAni / NiO nanoparticle, nanobelt, and nanotube in the presence of sodium dodecylbenzenesulfonate (SDBS). The composite materials showed improved conductivity and thermostability [8-10].

Electro-co-deposition is an effective way to make composite films with a large variety of tunable parameters and so has the advantage of convenient film control. Generally, PAni is synthesized by anodic polymerization of aniline in acidic aqueous solution [2]. Thus the electrochemical synthesis of organic-inorganic composites based on PAni and metal oxides are mostly conducted by selecting oxides which can be electrodeposited in low pH media [3, 11-13]. However, most oxides can only be electrodeposited from high $\mathrm{pH}$ media, which limits the formation of such PAni composites. Recently, we have demonstrated that it is feasible to form electroactive PAni in aqueous solutions of $\mathrm{pH} 2$ to 12 [14]. $\mathrm{PAni}_{-} \mathrm{SiO}_{2}$ and $\mathrm{PAni}-\mathrm{MnO}_{\mathrm{x}}$ composites 
were hence obtained $[15,16]$. Nickel oxide was reported to be electrodeposited either at a fixed potential between 0.7 and $1.2 \mathrm{~V}$ or by dynamic potential cycling in the potential range of $0 \sim 1.2 \mathrm{~V} v s . \mathrm{SCE}$ from $\mathrm{Ni}^{2+}$ in neutral to weak basic solutions [17-22]. It is therefore likely that PAni and nickel oxide can be co-deposited to form an organic-inorganic composite film. In this paper, we report the electro-co-deposition of $\mathrm{NiO}_{\mathrm{x}}$ and PAni and the electrochemical activities of the obtained composite film through cyclic voltammetry. The morphologies and elemental components of the film were inspected by Scanning Electron Microscopy (SEM) and Energy Dispersive X-ray Diffraction (EDX), respectively. Film stability in acidic condition was investigated and the electrocatalytic property of the composite film was demonstrated. 


\section{EXPERIMENTAL}

\section{Materials}

Aniline was distilled under vacuum before use. Other chemicals were of analytical grade and used as received. Electrochemical depositions were performed on electrochemical analyzer system, CHI 660B, on carbon cloth, using platinum plate and SCE as counter and reference electrode, respectively.

\section{Synthesis of PAni-NiOx composite film}

Prior to electrodeposition, the carbon cloth was cleaned by acetone followed by distilled water. Electrochemical co-deposition of $\mathrm{NiO}_{\mathrm{x}}$ and PAni was carried out in a solution containing $0.2 \mathrm{M} \mathrm{NiSO}_{4}$ and $0.005 \mathrm{M}$ aniline adjusted to $\mathrm{pH} 7.3$ by $\mathrm{H}_{2} \mathrm{SO}_{4}$ or $\mathrm{NaOH}$. Cyclic voltammetry (CV) with fixed scans (25 consecutive cyclic scans) between $-0.3 \sim 1.2 \mathrm{~V} v s$. SCE at $50 \mathrm{mV} \cdot \mathrm{s}^{-1}$ were performed. Pure nickel oxide and PAni films were electrodeposited similarly.

\section{PAni-NiOx film characterization}

Electrochemical activities of the films were studied by cyclic voltammetry at 50 $\mathrm{mV} \cdot \mathrm{s}^{-1}$ in $0.1 \mathrm{M} \mathrm{NaOH}$ and $0.1 \mathrm{M} \mathrm{H}_{2} \mathrm{SO}_{4}$ respectively. The morphologies of the film and the elemental components were inspected by Scanning Electron Microscopy (SEM) and Energy Dispersive X-ray Diffraction (EDX) on SHIMADZU SSX-550 Scanning Electron Microscope.

Stability of nickel oxide within the composite film in acidic solutions was investigated through cyclic voltammetry in $0.1 \mathrm{M} \mathrm{NaOH}$ at $50 \mathrm{mV} \cdot \mathrm{s}^{-1}$ after 
immersion for 3 hours in $\mathrm{H}_{2} \mathrm{SO}_{4}$ solutions of different $\mathrm{pH}(\mathrm{pH} 1.0,2.0,2.5,3.0,3.5$, 4.0). Electrochemical catalytic properties of the films were investigated by cyclic voltammetry at $5 \mathrm{mV} \cdot \mathrm{s}^{-1}$ in solution containing $1.0 \mathrm{M} \mathrm{NaOH}$ with different concentrations of $\mathrm{MeOH}$ and $\mathrm{EtOH}$. 


\section{RESULTS AND DISCUSSION}

\section{Synthesis of PAni-NiOx composite film}

Our previous work has shown that electroactive PAni film can be fabricated through electro-oxidative polymerization of aniline in aqueous solution at $\mathrm{pH} 2.0$ to 12.0 [14]. Nickel oxide film can generally be obtained from neutral to weak basic solutions of $\mathrm{Ni}^{2+}$ through similar electro-oxidation technique [17-21]. Thus, it is probable that PAni- nickel oxide composite film can be formed by electrochemical co-deposition from a single solution. Hence, by using a solution containing $0.2 \mathrm{M} \mathrm{Ni}^{2+}$ and $0.005 \mathrm{M}$ aniline adjusted to $\mathrm{pH} 7.3$, a composite film was successfully deposited onto the carbon cloth electrode.

Figure 1 shows the cyclic voltammograms (CV) obtained during the deposition process. Initially, a clear oxidation peak showed up at around 1.1 V vs. SCE. After the first scan, this oxidation current appeared to be much smaller. This is due to a number of factors that include proton generation from aniline oxidation (Scheme 1) which significantly reduced the amount of hydroxyl ions available for the $\mathrm{Ni}^{2+}$ oxidation $[23,24]$; secondly, the electrode surface was being deactivated (partially blocked) by the presence of polyaniline (PAni) film that reduced the mass transport process. However, it was observed that the current density increased gradually with successive scans after the initial drop, indicating that oxidation of $\mathrm{Ni}^{2+}$ still occurred readily but at a much slower rate on the electrode surface.

Similar conditions were used to deposit nickel oxide $\left(\mathrm{NiO}_{\mathrm{x}}\right)$ film. Figure 2 are the 
$\mathrm{CV}$ scans obtained during the deposition process. An oxidation peak appeared at $c a$. 1.1 V initially, which increased in height with progressive scans and gradually shifted to $c a .1 .2 \mathrm{~V}$. Simultaneously, there was also a distinct reduction peak started at $0.65 \mathrm{~V}$ which increased in current density with successive scans and shifted down to $0.5 \mathrm{~V}$.

The anodic electrochemical reactions are more complex but can be summarized as follows [25]:

$2 \mathrm{H}_{2} \mathrm{O} \rightarrow \mathrm{H}_{2}+2 \mathrm{OH}^{-}-2 \mathrm{e}^{-}$

$\mathrm{Ni}^{2+}+2 \mathrm{OH}^{-} \rightarrow \mathrm{Ni}(\mathrm{OH})_{2} \quad$ (chemical reaction on electrode surface)

$\mathrm{Ni}(\mathrm{OH})_{2}+\mathrm{OH}^{-} \rightarrow \mathrm{NiO}-\mathrm{OH}+\mathrm{H}_{2} \mathrm{O}+\mathrm{e}^{-}$

$\mathrm{NiO}-\mathrm{OH}+\mathrm{OH}^{-} \rightarrow \mathrm{NiO}_{2}+\mathrm{H}_{2} \mathrm{O}+\mathrm{e}^{-}$

Whereas the reduction reaction observed can be simplified as:

$\mathrm{NiO}_{2}+2 \mathrm{H}_{2} \mathrm{O}+2 \mathrm{e}^{-} \rightarrow \mathrm{Ni}(\mathrm{OH})_{2}+2 \mathrm{OH}^{-}$

Equations 3-5 suggest that the product obtained was a mixture of $\mathrm{NiO}_{2}$ and $\mathrm{NiO}-\mathrm{OH}$.

Both pure and composite films displayed characteristic $\mathrm{NiO}_{\mathrm{x}}$ electroactivities as previously reported for nickel oxides [5-7, 18] suggesting successful electro-codeposition of PAni and $\mathrm{NiO}_{\mathrm{x}}$ from a single solution. Comparing the oxidation current densities from the two separate deposition processes that produced the composite film and the $\mathrm{NiO}_{\mathrm{x}}$ film, it was expected that there were much less $\mathrm{NiO}_{\mathrm{x}}$ deposited into the composite film. This is confirmed by the CV scans of the two materials presented in Figure 3 that shows, according the current density observed, the composite film is estimated to contain less than a tenth of $\mathrm{NiO}_{\mathrm{x}}$ compared to the pure $\mathrm{NiO}_{\mathrm{x}}$ membrane. However, this estimation can only be used as a general indication because the electron transfer efficiencies and inherent electrical resistance between the pure and composite films are expected to be quite different. 


\section{Characterization of PAni- $\mathrm{NiO}_{\mathrm{x}}$ composite film}

Elemental analysis of PAni-NiOx composite and nickel oxide films were carried out by Energy Dispersive X-ray Diffraction (EDX) technique. Similar spectra were obtained for the two films which identified the presence of more than one form of nickel oxides (Figure 4). Therefore a mixture of $\mathrm{NiO}_{2}$ and $\mathrm{NiO}-\mathrm{OH}$ may co-exist in the film according to equations 3-5. Scanning Electron Microscopy (SEM) images of the films revealed very different surface morphologies. PAni- $\mathrm{NiO}_{\mathrm{x}}$ composite adopted a much smoother morphology consisting of aggregations of sub micron particles; whereas the nickel oxide film was made up of much bigger worm like tubules several microns long (Figure 5). As shown in Figure 5a, nickel oxide particles are indistinguishable from that of the PAni, which may suggest they are well dispersed in polymer network of the composite film. This may explain why the $\Delta E$ for $\mathrm{Ni}(\mathrm{II})$ / $\mathrm{Ni}(\mathrm{III})$ couple (shown in equation 3) obtained from the composite film is smaller than that obtained from the pure nickel oxide film as the fine dispersion of nickel oxide particle within the PAni network facilitates the electron exchange. However, the difference in $\Delta E$ observed may also be attributable to an uncompensated resistance effect.

\section{Electrochemical properties}

PAni-NiOx composite film displayed two pairs of redox peaks in $0.1 \mathrm{M} \mathrm{H}_{2} \mathrm{SO}_{4}$ which were similar to a PAni film made under similar conditions (Figure 6). The first couple at $c a .0 .2 \mathrm{~V}$ corresponded to the exchange between leucoemeraldine and emeraldine states of PAni. The second couple at $c a .0 .4 \mathrm{~V}$ was related to the exchange between 
emeraldine and pernigraniline [26]. However, these redox couples did not exist in alkaline solution as PAni was not electroactive under alkaline media (ca. $\mathrm{pH}>10.0$ ). Meanwhile, $\mathrm{NiO}_{\mathrm{x}}$ was unstable in acidic conditions as the compound dissolved relatively rapidly in acids. Figure 7 is a typical example of $\mathrm{CVs}$ obtained from a $\mathrm{NiO}_{\mathrm{x}}$ film at $\mathrm{pH}$ 2.1. The cathodic current reduced quickly with progressive scans and almost completely lost its activity after just 5 cycles. These contrasts in property had made the study of $\mathrm{PAni}_{-\mathrm{NiO}}$ composite film more challenging as solutions of two extreme $\mathrm{pHs}$ had to be used to investigate the activities of $\mathrm{PAni}$ and $\mathrm{NiO}_{\mathrm{x}}$ components, i.e. acidic media for PAni and alkaline for $\mathrm{NiO}_{x}$.

By comparing the cathodic current of the composite film at $0.25 \mathrm{~V} v s$. SCE to that of the pure nickel oxide film at $0.2 \mathrm{~V}$ vs SCE after 20 scan cycles, we have demonstrated that $\mathrm{PAni}-\mathrm{NiO}_{\mathrm{x}}$ composite film has enhanced stability in acidic media (Figure 8). The modified electrodes were immersed in acidic solutions ranging from $\mathrm{pH} 4.0$ to 1.0 for 3 hours before the cathodic current was measured in $0.1 \mathrm{M} \mathrm{NaOH}$. Results show that significant electro-activity could be detected for PAni- $\mathrm{NiO}_{\mathrm{x}}$ composite films at low $\mathrm{pHs}$ as detailed in Figure 8. The data showed that above $\mathrm{pH}$ 2.5 the composite film remained electrochemically active and was relatively stable; whereas the pure $\mathrm{NiO}_{\mathrm{x}}$ film was only stablised above $\mathrm{pH}$ 3.5. It was demonstrated that this simple technique for immobilization of nickel oxide into PAni matrix has resulted in a more stable material.

\section{Catalytic properties}

It is known that nickel oxide is an electrocatalyst for hydroxylated organic compounds 
$[5,6,27,28]$. It is envisaged that this composite material may retain and enhance the catalytic properties of the nickel oxide through fine dispersion of the catalyst particles into the conductive PAni matrix to result in a drastic increase in surface area. Additionally, the conductive PAni matrix, being closely associated to the nickel oxide catalyst as a result of co-deposited film, is expected to facilitate electron transfer during the electrocatalytic reaction. These effects were demonstrated in the catalytic oxidation of alcohols in alkaline media.

Figure 9 and 10 were data obtained during the electro-oxidation of methanol and ethanol respectively monitored by cyclic voltammetry. On addition of the substrates, large anodic current increases appeared above $0.3 \mathrm{~V}$ (vs. SCE) which was corresponding to the $\mathrm{Ni}(\mathrm{II})$ to $\mathrm{Ni}(\mathrm{III})$ transition, indicating that electro-catalytic oxidation of the alcohols had occurred. The catalytic anodic reactions are summarized as follows:

$$
\begin{array}{ll}
\mathrm{R}-\mathrm{OH}+\mathrm{Ni}^{\mathrm{III}} \mathrm{O}-\mathrm{OH} \rightarrow \mathrm{Ni}^{\mathrm{II}}(\mathrm{OH})_{2}+\mathrm{RO}^{\bullet} & \mathrm{R}=\mathrm{Me}, \mathrm{Et} \\
\mathrm{Ni}(\mathrm{OH})_{2}+\mathrm{OH}^{-} \rightarrow \mathrm{NiO}-\mathrm{OH}+\mathrm{H}_{2} \mathrm{O}+\mathrm{e}^{-} & \text {At anode }
\end{array}
$$

Figure 11 presents two very similar calibration plots using the data shown in figures 9 and 10 which show that the composite film exhibited very high catalytic efficiency for methanol and ethanol oxidation. Given that only small amount of nickel oxide catalyst was present in the composite film, very fast mass transport and efficient electron transfer must have achieved to produce the observed catalytic behavior.

These data also indicate that the composite film may offer an electrochemical way of detecting alcohols in aqueous media across a broad concentration range of ca. 2 $\mathrm{mM}$ to $400 \mathrm{mM}$. Detail sensing investigation is beyond the scope of this work and 
will be discussed elsewhere.

We have reported the synthesis and characterization of PAni- $\mathrm{NO}_{\mathrm{x}}$ composite film. This composite material is stable in $\mathrm{pH}>2.5$ and in basic environments and remains electrochemical active. The distinct physical configuration of the composite has led to enhanced catalytic properties which may have good potential in application areas such as electrocatalysis, sensing, and fuel cell etc. 


\section{CONCLUSIONS}

PAni-NiOx composite film was obtained through cyclic voltammetric technique in the solution containing $0.2 \mathrm{M} \mathrm{NiSO}_{4}$ and $0.005 \mathrm{M}$ aniline at $\mathrm{pH}$ 7.3. The cyclic voltammogram $(\mathrm{CV})$ of the composite film displayed well-defined anodic and cathodic peaks associated with $\mathrm{Ni}(\mathrm{II}) / \mathrm{Ni}$ (III) redox couple in $0.1 \mathrm{M} \mathrm{NaOH}$, which was similar to that of nickel oxide film. Nickel oxide particles were well dispersed in polymer network of the composite film and was witnessed by the facilitated $\mathrm{Ni}(\mathrm{II})$ / $\mathrm{Ni}(\mathrm{III})$ redox transition, enhanced catalytic activities and increased $\mathrm{NiO}_{\mathrm{x}}$ stability within the composite material. 


\section{Acknowledgments}

We gratefully acknowledge financial support from National Natural Science

Foundation of China (project number: 50372011), Natural Science Foundation of Liaoning Province, China (project number: 20052016) and the China-Ireland Collaboration Funding (co-funded by SFI, RCS and CMOST). The author (K Lau) also wishes to thank DCU fellowship award for financial support. 


\section{REFERENCE}

1. Pedro G-R (2001) Adv Mater 13: 163

2. Subramania A, Devi S-L (2008) Polym Adv Technol 19: 725

3. Shen P-K, Huang H-T, Tseung A-C-C (1992) J Electrochem Soc 139:1840

4. Karlsson J, Roos A (2000) Solar Energy 68: 493

5. Berchmans S, Gomathi H, Rao G-P (1995) J Electroanal Chem 394: 267

6. Cataldi T-R-I, Centonze D (1995) Anal Chim Acta 307: 43

7. Nam K-W, Yoon W-S, Kim K-B (2002) Elctrochim Acta 47: 3201

8. Song G-P, Bo J, Guo R (2005) Colloid Polym Sci 283: 677

9. Song G-P, Han J, Guo R (2007) Synth Met 157: 170

10. Han J, Song G-P, Guo R (2006) J Polym Sci, Part A: Polym Chem 44: 4229

11. Sun L-J, Liu X-X (2008) Eur Polym J 44: 219

12. Liu X-X, Bian L-J, Zhang L, Zhang L-J (2007) J Solid State Electrochem 11: 1279

13. Hu C-C, Chu C-H (2000) Mater Chem Phys 65: 329

14. Liu X-X, Zhang L, Li Y-B, Bian L-J, Su Z, Zhang L-J (2005) J Mater Sci 40: 4511

15. Liu X-X, Zhang L, Li Y-B, Bian L-J, Huo Y-Q, Su Z (2006) Polym Bull 57: 825

16. Sun L-J, Liu X-X, Lau K-K-T, Chen L, Gu W-M (2007) Electrochim Acta 53: 3036

17. Casella I-G, Spera R (2005) J Electroanal Chem 578: 55

18. Tench D, Warren L-F (1983) J Electrochem Soc 130: 869 
19. Prasad K-R, Miura N (2004) Appl Phys Lett 85: 4199

20. Chigane M, Ishikawa M (1992) J Chem Soc Faraday Trans 88: 2203

21. Yang M-C, Lin C-K, Su C-L (1995) J Electrochem Soc 142: 1189

22. Peng X-Y, Li W, Liu X-X, Hua P-J (2007) J Appl Polym Sci 105: 2260

23. Gospodinova N, Terlemezyan L (1998) Prog Polym Sci 23: 1443

24. Duic L, Mandic Z, Kovac S (1995) Electrochim Acta 40: 1681

25. Jayashree R-S, Kamath P-V (2001) J Power Sources 93: 273

26. Huang W-S, Humphrey B-D, MacDiarmid A-G (1986) J Chem Soc Faraday Trans 82: 2385

27. George M-V, Balachandran K-S (1975) Chem Reviews 75: 491

28. Casells I-G, Cataldi T-R-I, Salvi A-M, Desimoni E (1993) Anal Chem 55: 3143 


\section{FIGURE CAPTIONS}

Figure 1 Cyclic voltammograms obtained for the electro-co-deposition of composite film on carbon cloth from a solution containing $0.2 \mathrm{M} \mathrm{M} \mathrm{Ni}^{2+}$ and $0.005 \mathrm{M}$ aniline $(\mathrm{pH}=7.3)$. Scan rate: $50 \mathrm{mV} \mathrm{s}^{-1}$.

Figure 2 Cyclic voltammograms obtained for the electrodeposition of nickel oxide on carbon cloth from a solution of $0.2 \mathrm{M} \mathrm{Ni}^{2+}(\mathrm{pH}=7.3)$. Scan rate: 50 $\mathrm{mVs}^{-1}$.

Figure 3 Cyclic voltammograms of $\mathrm{PAni}_{-\mathrm{NiO}_{\mathrm{x}}}$ (a: solid line) and similarly prepared nickel oxide (b: dash line) films in $0.1 \mathrm{M} \mathrm{NaOH}$. Scan rate: 50 $\mathrm{mV} \mathrm{s}^{-1}$.

Figure 4 EDX spectra of (a) $\mathrm{PAni}-\mathrm{NiO}_{\mathrm{x}}$ and (b) $\mathrm{NiO}_{\mathrm{x}}$.

Figure 5 SEM images of (a) $\mathrm{PAni}-\mathrm{NiO}_{\mathrm{x}}$ composite and (b) similarly prepared nickel oxide films.

Figure 6 Cyclic voltammograms of $\mathrm{PAni}_{-\mathrm{NiO}_{\mathrm{x}}}$ (solid line) and similarly prepared PAni (dash line) films in $0.1 \mathrm{M} \mathrm{H}_{2} \mathrm{SO}_{4}$. Scan rate: $50 \mathrm{mV} \mathrm{s}^{-1}$.

Figure 7 Cyclic voltammograms of $\mathrm{NiO}_{\mathrm{x}}$ film in $\mathrm{H}_{2} \mathrm{SO}_{4}$ solution at $\mathrm{pH}$ 2.1. Scan rate: $50 \mathrm{mV} \mathrm{s}^{-1}$. a - e: cycles 1 to 5 showing progressive reduction in current density.

Figure 8 Normalized Percentage cathodic current density obtained after 20 scan cycles in $0.1 \mathrm{M} \mathrm{NaOH}$ for (a) nickel oxide (solid triangle) and (b) the PAni-NiOx composite (open circle) after the electrodes were immersed for 3 hours in various $\mathrm{H}_{2} \mathrm{SO}_{4}$ solutions of $\mathrm{pH} 1$ to 4 . $\left(i_{\mathrm{c}}\right)$ and $\left(i_{\mathrm{c}}{ }^{\prime}\right)$ denotes 
current obtained before and after acid immersion. Peak currents were obtained at $0.2 \mathrm{~V}$ and $0.25 \mathrm{~V}$ vs. SCE for nickel oxide and $\mathrm{PAni}-\mathrm{NiO}_{\mathrm{x}}$ composite films respectively.

Figure 9 Cyclic voltammograms of $\mathrm{PAni}-\mathrm{NiO}_{\mathrm{x}}$ composite film in $1.0 \mathrm{M} \mathrm{NaOH}$ and different concentrations of methanol. Scan rate: $5 \mathrm{mV} \mathrm{s}^{-1}$; concentration of methanol: a: 0 M, b: $0.006 \mathrm{M}$, c: $0.01 \mathrm{M}, \mathrm{d}: 0.02 \mathrm{M}$, e: $0.04 \mathrm{M}, \mathrm{f:} 0.2 \mathrm{M}$, g: $0.4 \mathrm{M}$, h: $0.6 \mathrm{M}, \mathrm{i}: 0.8 \mathrm{M}, \mathrm{j}: 1.0 \mathrm{M}$.

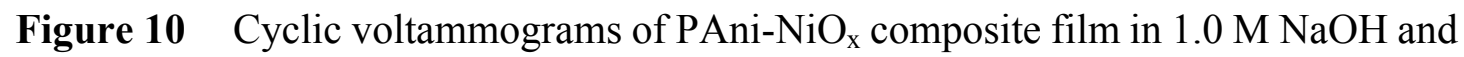
different concentrations of ethanol. Scan rate: $5 \mathrm{mV} \mathrm{s}^{-1}$; concentration of ethanol: a: 0 M, b: $0.02 \mathrm{M}$, c: $0.06 \mathrm{M}, \mathrm{d}: 0.08 \mathrm{M}$, e: $0.2 \mathrm{M}$, f: $0.4 \mathrm{M}$, g: $0.6 \mathrm{M}, \mathrm{h}: 0.8 \mathrm{M}, \mathrm{i}: 1.0 \mathrm{M}$.

Figure 11 Calibration plot for the electrocatalytic oxidation of methanol (a: open square) and ethanol (b: solid triangle) on the PAni-NiOx composite film.

Scheme 1 Electro-polymerization of aniline showing protons being generated during the anodic oxidation process. 